\title{
The UCISA Community and its achievements: UK good practice resources
}

\author{
Anna Mathews ${ }^{1}$, Peter Tinson ${ }^{2}$ \\ ${ }^{1}$ Universities and Colleges Information Systems Association, University of Oxford, 13 Banbury Road, \\ Oxford, OX2 6NN, UK execsec@ucisa.ac.uk \\ ${ }^{2}$ Universities and Colleges Information Systems Association, University of Oxford, 13 Banbury Road, \\ Oxford, OX2 6NN, UK execsec@ucisa.ac.uk
}

Keywords

Best practice, communities of practice, special interest groups, resources.

\section{ABSTRACT}

UCISA, the Universities and Colleges Information Systems Association, is a membership organisation representing those responsible for delivering information management systems and technology services in universities, colleges and other institutions. UCISA membership is institutional and has almost $100 \%$ coverage within the higher education sector in the UK. UCISA also has over 90 corporate members.

UCISA's aims are to promote best practice through events, awards, and publications, and to represent the interests of its members through lobbying, responding to consultations, and building relationships with other groups (typically through UCISA's active involvement in committees and working parties).

The poster showcases the achievements of the UCISA community, with particular attention to the resources produced by UCISA's specialist interest groups and communities of practice. Recent examples include: an information security toolkit which 15 universities have used to derive policies from; a briefing paper on cloud computing aimed at non-technical senior managers; an ITIL readiness assessment tool; a guide for engaging with academics in the use of technology enhanced learning and case studies on the provision of wireless access.

UCISA publications, case studies and event materials (presentations, streamed content and other post-event resources) are freely available to colleagues across the UK and internationally at www.ucisa.ac.uk

\section{AUTHORS' BIOGRAPHIES}

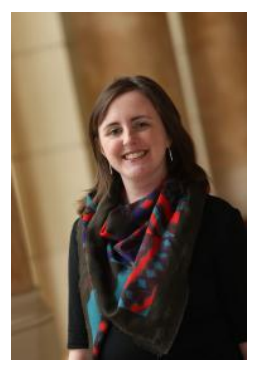

Anna Mathews is UCISA's Head of Policy and Projects. She drafts UCISA's consultation responses and represents the Association at meetings and events. Anna also works in collaboration with UCISA's special interest groups and leads the annual statistics survey. Before joining UCISA in May 2009, Anna worked in programme management and academic administration for the University of Oxford; was employed as a clinical trials network coordinator for the National Health Service (NHS) and was a freelance public relations consultant, specialising in business to business promotion.

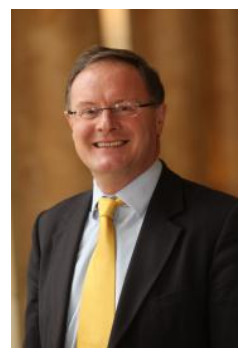

As UCISA Executive Secretary, Peter Tinson heads the UCISA Office and works with the Chair and Executive on the strategic direction of the Association. He is also responsible for maintaining and developing working relationships with external agencies and key stakeholders as well as other professional and national organisations. Prior to joining UCISA in May 2005, Peter held a number of posts at City University, London and was responsible for policy and procedure including the conditions for use for the network and institutional computers. 